\title{
Optimal reference genes for gene expression analysis in polyploid of Cyprinus carpio and Carassius auratus
}

\author{
Wenbin Liu ${ }^{1,2}$, Xiudan Yuan ${ }^{1,2}$, Shuli Yuan ${ }^{1,2}$, Liuye Dai ${ }^{1,2}$, Shenghua Dong ${ }^{1,2}$, Jinhui Liu ${ }^{1,2}$, Liangyue Peng ${ }^{1,2}$,
} Minmeng Wang ${ }^{1,2}, Y_{i}$ Tang $^{1,2}$ and Yamei Xiao ${ }^{1,2^{*}}$ (i)

\begin{abstract}
Background: Reference genes are usually stably expressed in various cells and tissues. However, it was reported that the expression of some reference genes may be distinct in different species. In this study, we intend to answer whether the expression of reported traditional reference genes changes or not in the polyploid fish

Results: By retrieving the mRNA sequencing data of three different ploidy fish from the NCBI SRA database, we selected 12 candidate reference genes, and examined their expression levels in the 10 tissues and in the four cell lines of three different ploidy fish by real-time PCR. Then, the expression profiles of these 12 candidate reference genes were systematically evaluated by using the software platforms: BestKeeper, NormFinder and geNorm.

Conclusion: The 28 S ribosomal protein S5 gene (RPS5) and the ribosomal protein S18 gene (RPS18) are the most suitable reference genes for the polyploid of Cyprinus carpio and Carassius auratus, demonstrated by both of the tissues and the cultured cells.
\end{abstract}

Keywords: Reference gene, Polyploid fish, RPS5, RPS18

\section{Background}

Reference genes, generally known as the housekeeping genes, are a type of genes not only stably expressed in various cells but also less affected by external factors [1,2]. A number of reference genes have been widely used in molecular biology research, such as the beta-actin ( $\beta$-actin), beta-tubulin ( $\beta$-tubulin), elongation factor 1-alpha (EF1- $\alpha)$, Glyceraldehyde-3phosphate dehydrogenase (GAPDH), ribosomal protein S18 (RPS18), etc. [3-7]. However, it was reported that the expression of some traditional reference genes could change in varying degrees in various species or under

\footnotetext{
* Correspondence: yameix@hunnu.edu.cn

${ }^{1}$ State Key Laboratory of Developmental Biology of Freshwater Fish, College of Life Sciences, Hunan Normal University, Changsha 410081, Hunan, P.R. China

${ }^{2}$ College of Life Sciences, Hunan Normal University, Changsha 410081 Hunan, P.R. China
}

different experimental conditions [8-11]. For example, $\beta$ actin was the most common reference gene, and was stablely expressed in carrot (Daucus carota) under the abiotic stress and hormone stimuli, but it is not true in parsley even under the same experimental conditions [12, 13]. Similarly, the expression of $\beta$-tubulin was not stable during fruit development in cherry (Cerasus pseudocerasus) [14], and in different tissues of Siniperca chuatsie [15]. Although GAPDH was one of the most stable reference genes in the context of whitefly Bemisia tabaci (Asia I) thermal stress [10], Zhang et al found that it was distinctly expressed in different tissues of Spanish mackerel [16].

Polyploids are the organisms containing three or more complete sets of chromosomes [17]. They are widespread in plants [18-23], and around two hundreds of polyploids have been reported in insect and vertebrate [24-28]. Moreover, the polyploidy can be also found in

C C The Author(s). 2020 Open Access This article is licensed under a Creative Commons Attribution 4.0 International License, which permits use, sharing, adaptation, distribution and reproduction in any medium or format, as long as you give appropriate credit to the original author(s) and the source, provide a link to the Creative Commons licence, and indicate if changes were made. The images or other third party material in this article are included in the article's Creative Commons licence, unless indicated otherwise in a credit line to the material. If material is not included in the article's Creative Commons licence and your intended use is not permitted by statutory regulation or exceeds the permitted use, you will need to obtain permission directly from the copyright holder. To view a copy of this licence, visit http://creativecommons.org/licenses/by/4.0/. The Creative Commons Public Domain Dedication waiver (http://creativecommons.org/publicdomain/zero/1.0/) applies to the data made available in this article, unless otherwise stated in a credit line to the data. 
cells and tissues of diploid organisms, such as muscle tissues, megakaryocytes, and hepatocytes [29, 30]. Polyploidization leads to chromosome doubling and genome structural variation [31-33]. Adams et al. described some significant changes in reference gene expression and the silencing of some homologous genes in different organs of heteropolyploid cotton [34]. We reasoned that polyploidy might affect the stable expression of conventional reference genes. Therefore, to reduce errors and ensure the authenticity and reliability of data, it is necessary to choose the most appropriate reference genes for different ploidy cells or organisms.

The tetraploid hybrid of $C$. auratus $(+) \times C$. carpio $L$. $(\delta)$, and the triploid hybrid of $C$. auratus $(+9) \times$ tetraploid hybrid $\left({ }^{\lambda}\right)$, generated by hybridization of Carassius auratus (C. auratus) and Cyprinus carpio (C. carpio), have important theoretical significance in polyploid animal research and remarkable economic benefits [35-37]. To investigate whether there were any changes in the expression of reference genes in varied ploidy fish, we obtained mRNA sequencing (seq) data of the diploid, triploid, and tetraploid fish from the NCBI SRA database [38-41], then chosed 12 candidate reference genes, and examined their expression in 10 tissues and four cell lines of three different ploidy fish by real-time PCR. Finally, we identified the most suitable reference genes for polyploid fish using stability evaluation tools, such as the BestKeeper, NormFinder and geNorm.

\section{Results}

Validation of reference genes by transcriptome analysis

We chosed 12 commonly used reference genes from our literature search. We retrieved the data of twelve candidate genes shown in Table 1 from the transcriptome. We assigned those genes with an adjusted $P$-value $<0.05$ and $\mid \log 2$ FoldChange $\mid>1.5$ found by DE Seq as differentially expressed $[42,43]$. Fold change refers to the ratio of expression difference between two samples. In the polyploidy tissues, the |log2FoldChange $\mid$ of $\beta$-actin between the triploid hybrid $(3 \mathrm{~N})$ and the diploid $C$. auratus $(2 \mathrm{~N})$ was greater than 1.5 , and the $P$-value of $B 2 M$ was less than 0.05; while between the tetraploid hybrid (JL4N) and the diploid C. auratus, the |log2FoldChange| of RPL7, RPLP2, RPL13 $\alpha, G A P D H$ were all greater than 1.5 , and the P-values of RPS5, RPL7, RPL13 $\alpha, E F 1-\alpha$, $G A P D H$ were less than 0.05 . In cultured cells, the $\mid \log 2-$ FoldChange| of candidate genes between the tetraploid hybrid cultured fin cells and diploid $C$. auratus cultured fin cells were all less than 1.5 , the $P$ values of $R P S 18$, $R P L P 2, R P L 13 \alpha, B 2 M$ were less than 0.05; The |log2FoldChange| of candidate genes between SP4N cells (SP4N) and diploid C. auratus cultured fin cells were all less than 1.5 , the $P$-value of $B 2 M$ was less than 0.05 . Based on the transcriptome data, we found that the expression of some traditional reference genes was unstable in polyploidy, such as the $\beta$-actin.

\section{Analysis of qPCR cycle threshold value}

First, we confirmed the ploidy level and DNA content of each sample by flow cytometry (Figure S1, S2). Then we examined the expression of twelve candidate reference genes in tissues and cultured cells of different ploidy fish using Real-time quantitative PCR (qPCR). The qPCR cycle threshold $(\mathrm{Ct})$ values were used to represent the level of mRNA transcription [44]. Based on the data of qPCR (Figure S3, S4), the Ct values for some of the selected reference genes varied significantly (Fig. 1). The RPS5, RPS18, RPL7and EF1- $\alpha$ were highly expressed in polyploidy tissues, while RPS18, RPL7,EF1- $\alpha$ and $\beta$-actin exhibited high expression in cultured cells. These results showed that in polyploid tissues, the expression of RPS5, RPS18, and RPL7 was more stable than that of $B 2 M$ and $G A P D H$. On the other hand, in cultured cells of different polyploid, the expression of EF1- $\alpha, R P S 5$ and RPS18 was stable, while that of $B 2 M$ and $G A P D H$ was not.

\section{Bestkeeper analysis}

The Bestkeeper program was further used to validate the relatively stable reference genes [5]. BestKeeper ranks the reference genes according to the stability of gene expression based on the two parameters: the standard deviations (SD) and the coefficient of variance $(\mathrm{CV})$ of expression levels. The lower SD and CV values, the higher stability [45]. Among the 10 different tissues of tetraploid hybrid and triploid hybrid $C$. auratus, only the SD value of RPS18 gene was less than 1, while the SD values of the other 11 genes were all greater than 1 , indicating they were not suitable for the use of reference gene. The order of expression stability from high to low was RPS18, RPS5, RPL7, RPL13 $\alpha, E F 1-\alpha, R P L P 2, D D X 5$, $\beta$-actin, $\beta$-tubulin, hprt1, GAPDH, and $B 2 M$ in the 10 tissues of different polyploid fish (Table 2). In the cultured cells, the SD values of $\beta$-actin, $\beta$-tubulin, GAPDH, $B 2 M$ were all higher than 1 , suggesting they were not ideal candidates of reference genes. The expression stability ranking from high to low was EF1- $\alpha, R P S 5$, RPS18, RPL7, DDX5, RPL13 $\alpha$, RPLP2, hprt1, $\beta$-actin, $\beta$ tubulin, GAPDH and B2M (Table 2).

\section{NormFinder analysis}

The NormFinder software applies a mathematical model to estimate the variation of the candidate reference genes (intra- and inter-group expression variations) [46]. To determine stable reference genes, we analyzed the data obtained from the qPCR using NormFinder [47]. As shown in Fig. 2, in the 10 tissues of different polyploid fish, the ranking of expression stability from high to low was RPLP2, RPS5, RPL7, RPS18, RPL13 $\alpha$, 


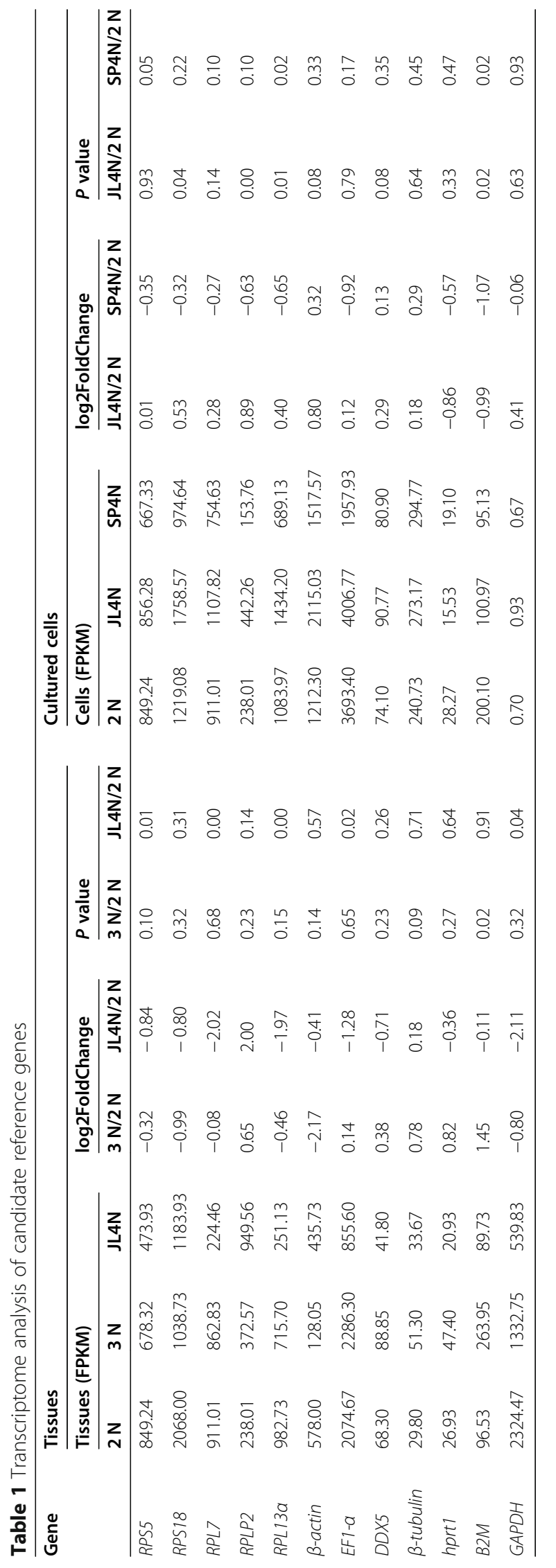




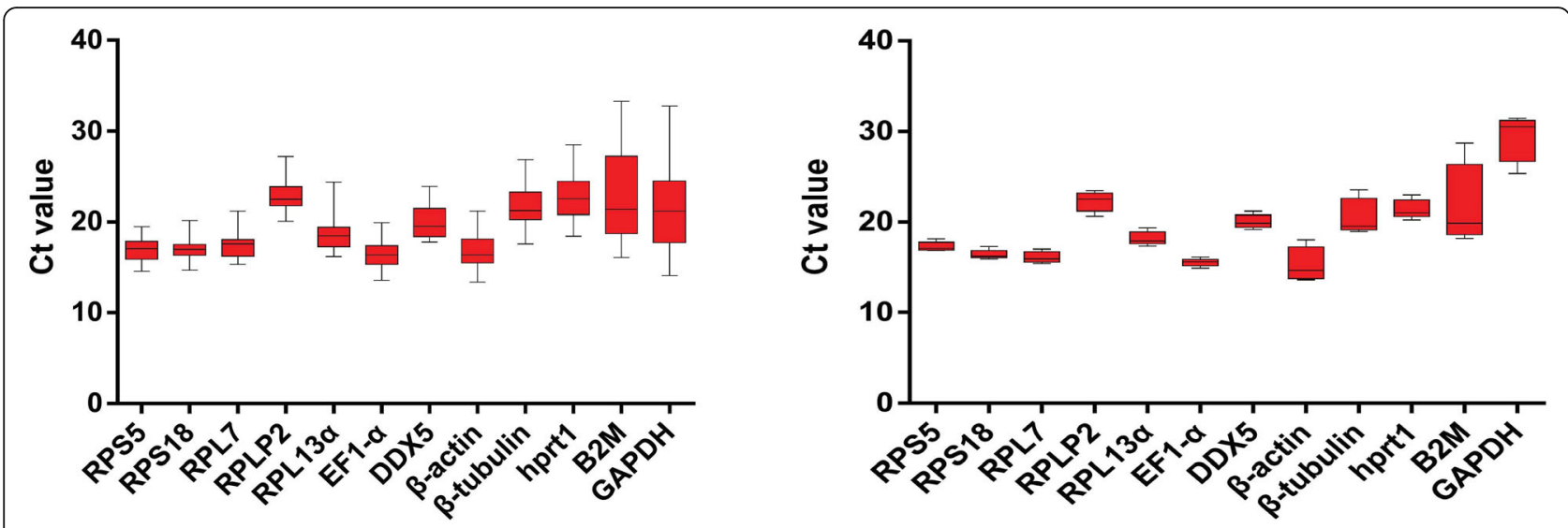

Fig. 1 The qPCR cycle threshold (Ct) values of candidate reference genes in tissues (Left) and cultured cells (Right) of different ploidy fish. The red area represented the range of $\mathrm{Ct}$ value variation

DDX5, EF1- $\alpha, \beta$-actin, hprt1, $\beta$-tubulin, B2M, and GAPD $H$. In the cultured cells of different polyploid, the ranking of stability was, from high to low, RPS18, RPS5, DDX5, RPL13 $\alpha$, RPL7, hprt1, EF1- $\alpha$, RPLP2, $\beta$-actin, $\beta$ tubulin, GAPDH, and B2M (Fig. 2).

\section{GeNorm analysis}

GeNorm calculates value $M$ based on the pairwise variation between an individual gene and all other tested candidate genes. The $\mathrm{M}$ value is inversely proportional to the stability of particular reference genes. In general, if the $M$ value is less than 1.5 , it can be used as an alternative reference gene [12]. The program can also determine the optimal number of reference genes by pairwise difference analysis of normalized factors [45, 48]. As shown in Fig. 3, in the 10 different tissues of diploid $C$. auratus, triploid hybrid and tetraploid hybrid, the

Table 2 The expression stability of candidate reference genes in tissues and cultured cells of different ploidy fish assessed by the Bestkeeper software

\begin{tabular}{|c|c|c|c|c|c|c|}
\hline \multirow[t]{2}{*}{ Gene } & \multicolumn{3}{|c|}{ Tissues } & \multicolumn{3}{|c|}{ Cultured cells } \\
\hline & SD & CV & Rank & SD & CV & Rank \\
\hline RPS5 & 1.06 & 6.24 & 2 & 0.38 & 2.19 & 2 \\
\hline RPS18 & 0.18 & 4.75 & 1 & 0.4 & 2.45 & 3 \\
\hline RPL7 & 1.15 & 6.58 & 3 & 0.44 & 2.73 & 4 \\
\hline$R P L P 2$ & 1.3 & 5.7 & 6 & 0.78 & 3.5 & 7 \\
\hline RPL13a & 1.23 & 6.61 & 4 & 0.57 & 3.15 & 6 \\
\hline EFI- $a$ & 1.3 & 7.85 & 5 & 0.3 & 1.9 & 1 \\
\hline DDX5 & 1.4 & 7.04 & 7 & 0.56 & 2.79 & 5 \\
\hline$\beta$-actin & 1.54 & 9.24 & 8 & 1.46 & 9.58 & 9 \\
\hline$\beta$-tubulin & 1.76 & 8.11 & 9 & 1.54 & 7.54 & 10 \\
\hline hprt1 & 1.87 & 8.22 & 10 & 0.8 & 3.77 & 8 \\
\hline$B 2 M$ & 4.83 & 20.71 & 12 & 3.49 & 16.19 & 12 \\
\hline GAPDH & 3.91 & 18.34 & 11 & 2.05 & 6.95 & 11 \\
\hline
\end{tabular}

expression stability in descending order was listed by RPS5, RPS18, RPL7, RPLP2, RPL13 $\alpha$, $\beta$-actin, EF1- $\alpha$, $D D X 5, \beta$-tubulin, hprt1 B2M and GAPDH. Their $M$ values were given by $0.183,0.183,0.936,0.988,1.048$, $1.208,1.290,1.361,1.455,1.558,2.159$ and 2.655 , respectively In the cultured cells of C. auratus, triploid hybrid, tetraploid hybrid and SP4N cell line, the $M$ values of RPS5, RPS18, RPL7, RPLP2, RPL13 $\alpha$, $\beta$-actin, EF1- $\alpha$, $D D X 5$, $\beta$-tubulin, hprt1, B2M, and GAPDH were 0.143 , $0.143,0.211,0.520,0.250,0.684,0.447,0.281,0.812$, $0.350,1.696$, and 1.100, respectively (Fig. 3).

In addition, the pairwise variation $\mathrm{V}$ calculated by geNorm was also used to determine the minimum number of the reference genes for optimal normalization: If the $\mathrm{Vn} / \mathrm{Vn}+1$ value was $<0.15$, the number of optimal reference genes was $n$, and if the $V n / V n+1$ value was $>$ 0.15 , the optimal number of reference genes was $n+1$ $[10,11]$. As shown in Fig. 4 , the $\mathrm{Vn} /(\mathrm{n}+1)$ values in the polyploid tissues were all greater than 0.15 , while those of polyploid cultured cells, the V2/3 were less than 0.15 . The results suggested that two reference genes should be combined for optimal normalization polyploid cultured cells, while it was necessary to adjust the conditions accordingly to determine the appropriate number of reference genes.

\section{Discussion}

In this study, 12 traditional reference genes were selected as candidate reference genes after literature search [3-7], then subjected to transcriptome analysis. These 12 relatively stable candidate reference genes in polyploid of Cyprinus carpio and Carassius auratus were evaluated using BestKeeper, NormFinder and geNorm, three reference gene stability analysis softwares that are widely used in the reference gene selection in species such as animals, micro-organisms and plants [45, 47-50]. For the polyploid tissues, the top three stable reference genes 

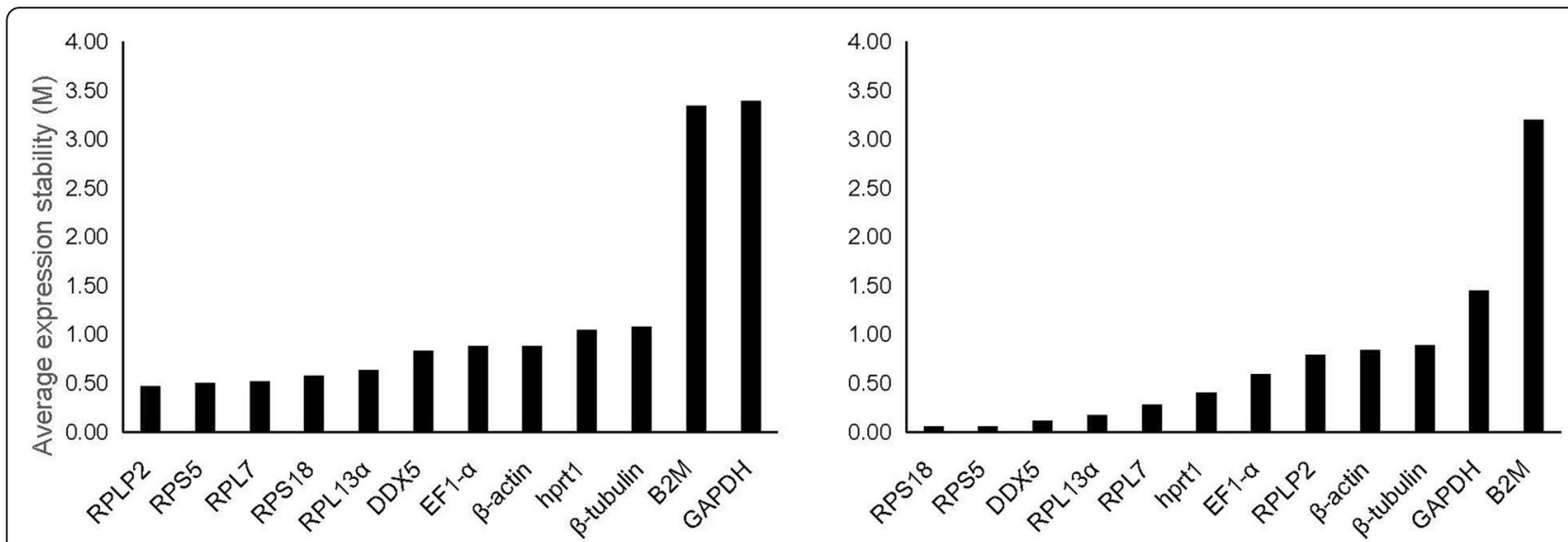

Fig. 2 The expression stability of candidate reference genes in the tissues (Left) and cultured cells (Right) of different ploidy fish assessed by the NormFinder software

evaluated by BestKeeper were RPS18, RPS5 and RPL7, those by NormFinder were RPLP2, RPS5 and RPL7, and those by geNorm were RPS5, RPS18 and RPL7. As for the polyploid cultured cells in vitro, the top three stable reference genes evaluated by BestKeeper were EF1- $\alpha$, RPS5 and RPS18, those by NormFinder were RPS18, RPS5 and $R P L P 2$, and those by geNorm were RPS5, RPS18 and $R P L 7$. Our data showed that the expression levels of RPS5 and RPS18 were relatively stable not only in the polyploid fish tissues in vivo but also in the cultured cells in vitro.

For some reasons, such as extreme conservativation of evolution, highly and stably expression in different types of cells and tissues, several components of ribosomes were selected as reference genes [47, 51-55]. In eukaryotic cells, the ribosomal RNA (rRNA) genes exist in multiple copies, however, without poly (A) tail, rRNA could not be reversely transcribed in cDNA synthesis using oligo (dT) as a primer [53, 54, 56]. Both RPS5 and RPS18 are the ribosomal protein genes, which were highly expressed in the eukaryotic organisms [52]. The RPS5 was closely related to transcription elongation factor-3 and DNA connection protein II, and its expression was highly conserved [47, 57-63]. RPS18, a highly conserved member of the nuclear protein S13 superfamily, is one of the constituent proteins of the eukaryotic ribosomal $40 \mathrm{~S}$ subunit, and stably expressed in different tissues [34, 64-68]. Therefore, with the high expression level and best stability, we selected RPS5 and RPS18 as the suitable reference genes in the polyploid of Cyprinus carpio and Carassius auratus.

Moreover, in line with the settings of the geNorm software, in polyploid cultured cells, the pairwise variation analysis showed that the $\mathrm{V} 2 / 3<0.15$, but all $\mathrm{Vn} /$ $\mathrm{Vn}+1$ values were greater than 0.15 in the polyploid tissues. Cao et al encountered a similar problem in the selection of reference genes of Ruditapes philippinarum $[69,70]$. It indicated that the two reference genes were sufficient for the gene expression normalization of the polyploid cultured cells, but it was necessary to adjust the conditions accordingly to determine an appropriate number of the reference genes in the polyploid tissues.

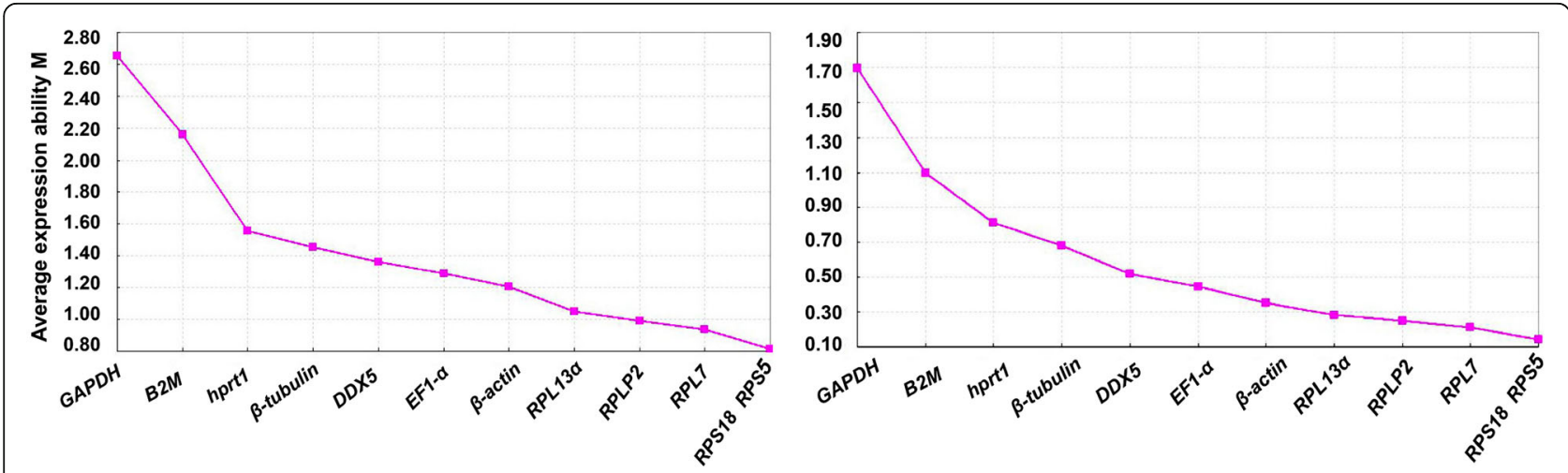

Fig. 3 The stability of candidate reference genes in tissues (Left) and cultured cells (Right) of different ploidy fish determined by GeNorm analysis 

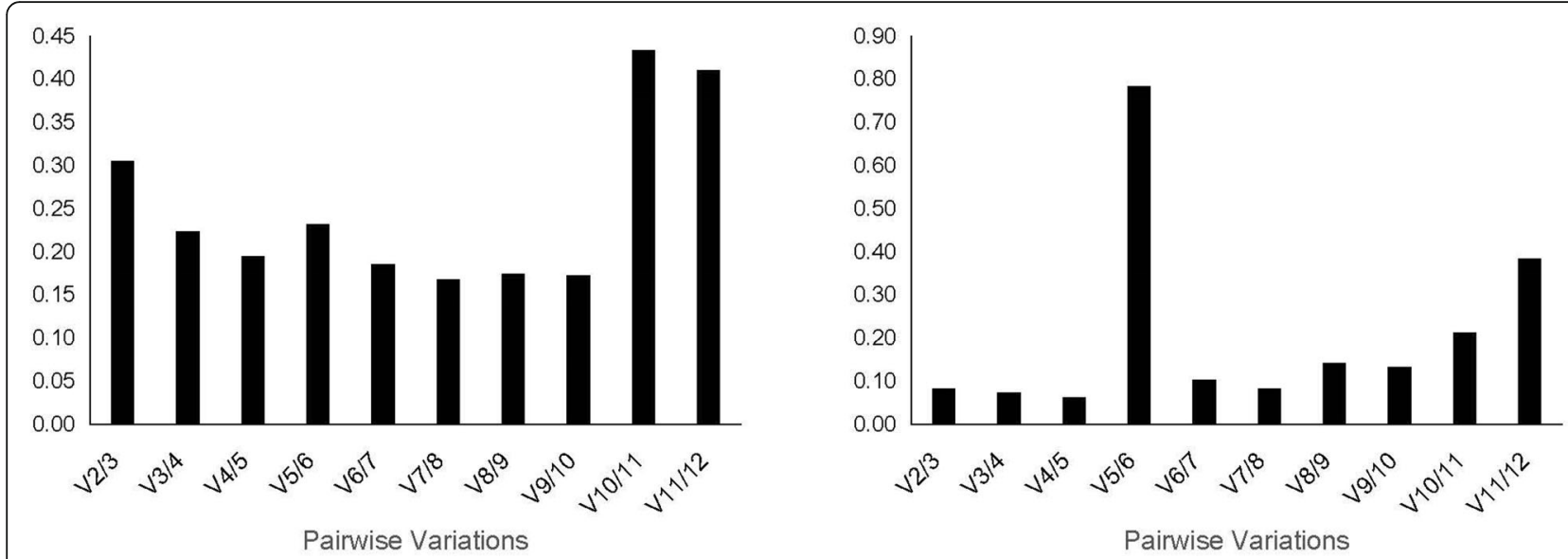

Fig. 4 Optimal number of reference genes for normalization of gene expression in tissues (Left) and cultured cells (Right). The geNorm was used to calculate the pairwise variation $(V n / N n+1$, the " $n$ " represents the number of reference genes)

\section{Conclusion}

In this study, we systematically evaluated the expression profiles of 12 selected candidate reference genes of the polyploid fish using BestKeeper, NormFinder and geNorm, and determined a comprehensive ranking of these genes. We confirmed that RPS5 and RPS18 were the most stable reference genes across different tissues and cultured cells for polyploid of Cyprinus carpio and Carassius auratus. These reference genes identified in this study will become useful tools for the molecular biology of polyploid fish.

\section{Methods}

\section{Ethics statement}

All sampling procedures were conducted in accordance with the standards and ethical guidelines established by the Animal Ethical Review Committee, Hunan Normal University, Changsha, China.

\section{Sample preparation}

Fish, including C.auratus ( $2 \mathrm{~N}$ ), tetraploid hybrid (JL4N) of C.auratus (+) $\times$ C. carpio L. $\left(\oint^{\lambda}\right)$, and triploid hybrid (3 $\mathrm{N})$ of $C$. auratus $(+) \times$ tetraploid hybrid $\left({ }^{\top}\right)$, were bred and fed in pools under the same water temperature, dissolved oxygen content, and for aging conditions at the Engineering Research Center of Polyploid Fish Breeding and Reproduction of the State EducationMinistry, China. Three individuals (1-year-old) of each species were collected for further study. Under aseptic conditions, ten tissues, e.g. liver, kidney, heart, spleen, brain, caudal fin, skin, muscle, intestine and gonad, were dissected from above three different ploidy fish, respectively.

Cultured cells were obtained from the caudal fin of $C$. auratus, triploid hybrid, and tetraploid hybrid. The SP4N cell line $(\mathrm{SP} 4 \mathrm{~N})$ was obtained from $C$. auratus caudal fin cells induced by the c-Jun $\mathrm{N}$-terminal kinase inhibitor SP600125 in vitro [39]. The cells were cultured in the Dulbecco's modified Eagles medium (DMEM; Sigma) supplemented with $100 \mathrm{U} / \mathrm{ml}$ penicillin, $100 \mu \mathrm{g} /$ $\mathrm{ml}$ streptomycin (Invitrogen, Carlsbad, CA, USA), 10\% fetal bovine serum (FBS, Invitrogen, Carlsbad, CA, USA), 0.1\% 2-mercaptoethanol (2-ME, Invitrogen, Carlsbad, CA, USA), $1 \mathrm{mM}$ sodium pyruvate (Invitrogen, Carlsbad, CA, USA), and $1 \mathrm{mM}$ nonessential amino acids (Invitrogen, Carlsbad, CA, USA). Cells were grown in $5 \%(\mathrm{v} / \mathrm{v}) \mathrm{CO}_{2}$ at $28^{\circ} \mathrm{C}$.

\section{RNA isolation}

Total RNA was isolated from tissues and culture cells of three different ploidy fish, using Trizol Reagent (Invitrogen, USA) following manufacturer protocols [71]. The quality of total RNA was detected by $1 \%$ agarose gel electrophoresis and nucleic acid analyzer [5].

\section{Transcriptome data obtaining and analysis}

We obtained mRNA sequencing (RNAseq) data of the liver tissue of diploid C. auratus, triploid hybrid and tetraploid hybrid from the NCBI Sequence Read Archive (SRA) database (Accession numbers: diploid C. auratus: SRR538839, SRR542431; triploid hybrid: SRR9185090, SRR9203584; tetraploid hybrid: SRR1535135, SRR1536195;) [38, 39]. And the RNAseq data of the cultured cells of diploid C. auratus, tetraploid hybrid, and SP4N cells also were obtained from the NCBI SRA database (Accession number: cultured cells of diploid C. auratus: SRR7640868, SRR7640869; cultured cells of tetraploid hybrid: SRR7640866, SRR7640867; SP4N cells: SRR9964682, SRR9964683) [40, 41].

All accessions and biological replicates were normalized using the method of DESeq2 [71], and three biological replicates were used in each analysis. The negative effects of background noise were eliminated by removing those low read counts of transcripts $(\leq 2)$ from 
the datasets. The values of fragments per kilobase of transcript per million mapped reads (FPKM) were used to analyze differential expression (DE) between diploid and triploid or diploid and tetraploid [72, 73].

The FPKM threshold 0.1 was set to determine whether the gene was expressed, where transcripts with FPKM $\leq 0.1$ were defined as no expression [74]. The higher the FPKM value, the stronger the gene expression. For polyploidy tissues, we used the transcriptome of diploid C. auratus liver as a reference, calculated the log2FoldChange between triploid hybrid and diploid, and $\log 2-$ FoldChange between tetraploid hybrid and diploid. For polyploid cultured cells, the transcriptome of diploid $C$. auratus cultured fin cell was used as a reference, we calculated the $\log 2$ FoldChange between tetraploid hybrid cultured fin cells and diploid cultured fin cells, and $\log 2-$ FoldChange between SP4N cells and diploid cultured fin cells. The difference in gene expression was evaluated according to log2Fold Change [62], which was calculated based on the FPKM value. As to the transcriptome data constructed in our laboratory, we cacluated the FPKM values of some common reference genes and performed multiple sequence alignment on these genes. Alignments of multiple sequences were used to ensure that the sequence similarity of the ortholog genes in different ploidy fish was above $99 \%$.

\section{Real-time quantitative PCR (qPCR)}

The reference genes were identified by bioinformatics analysis. The qPCR primers were designed using the Olig7 software and listed in Table S2. The cDNAs were synthesized according to the manual of the TaKaRa reverse transcription kit. Genomic DNA was first eliminated from the RNA. For reverse transcription, $1 \mu \mathrm{g}$ RNA was used for each reaction. For PCR, the five-fold dilution series of template cDNA was used. Each biological replicate was run in triplicate on a Bio-Rad CFX-96 system. Each $10 \mu \mathrm{L}$ qPCR reaction mixture contains $1 \mu$ Lof cDNA $(0.01 \mu \mathrm{g}$ RNA $), 5 \mu \mathrm{L}$ of Brilliant SYBR Green QPCR Master Mix and primer pair. SetNTC (No template control) negative controls for each sample, negative control reactions were included in all assays by substituting water for template DNA to confirm that no DNA contamination was present in RNA samples [10, 51, 52]. Each thermal cycle consisted of an initial polymerase activation step at for $50^{\circ} \mathrm{C}$ for 2 min and $95^{\circ} \mathrm{C}$ for $10 \mathrm{~min}$, followed by 40 cycles at $95^{\circ} \mathrm{C}$ for $15 \mathrm{~s}$, at $60^{\circ} \mathrm{C}$ for $1 \mathrm{~min}$. Afterwards, melting curves were generated to confirm a single gene-specific peak and to detect primer dimer formation by heating the samples stepwise from $60^{\circ} \mathrm{C}$ to $95^{\circ} \mathrm{C}$ while continuously monitoring the fluorescence. For each sample, the qPCR analysis was performed on three biological replicates. The specificity of all qPCR was confirmed by melting curve analysis of amplification products (Figure S5) [75]. To evaluate the expression levels of all candidate references across different tissues and cells of different ploidy fish, comparative analysis of all acquired $\mathrm{Ct}$ values for each gene, lower $\mathrm{Ct}$ values represents higher mRNA transcript levels [14].

\section{Evaluation of gene expression stability}

The $\mathrm{Ct}$ values calculated from qPCR data were used for further analyses. The stability of reference genes was evaluated by the Bestkeeper, NormFinder and geNorm $[47,49,76]$. The BestKeeper program is an excel spreadsheet with built-in formulas, the input $C P$ value is the average $\mathrm{Ct}$ value obtained from each biological replicate in qPCR. For NormFinder and geNorm, the quantification cycle $(\mathrm{Ct})$ values were transformed into relative quantities using the formula $2^{-\Delta \mathrm{Ct}}$, where $\Delta \mathrm{Ct}=$ each corresponding $\mathrm{Ct}$ value-the minimum $\mathrm{Ct}$ value. NormFinder applies a mathematical model to estimate the variation of the candidate reference genes. GeNorm calculated the expression stability measurement (M-value), which was based on the average variation in the expression level of a particular gene against that of all the control genes [14]. This programme also evaluates the pairwise variation $(\mathrm{Vn} / \mathrm{Vn}+1)$ to determine the optimal number of genes required for accurate normalization of qPCR data. Finally, a comprehensive analysis and comparison of the results of three software to evaluate the stability of candidate reference genes in different tissues and cells of different ploidy fish.

\section{Supplementary information}

Supplementary information accompanies this paper at https://doi.org/10. 1186/s12863-020-00915-6.

Additional file 1: Figure S1. Fish DNA content detection.

Additional file 2: Figure S2. Cell DNA content detection.

Additional file 3: Figure S3. Real-time quantitative $C T$ values of candidate reference genes in ten different tissuesof different ploidy fish.

Additional file 4: Figure S4. Real-time quantitative $C T$ values of candidate reference genes in cultured cells of different ploidy fish.

Additional file 5: Table S1. Evaluation of candidate reference genes in tissues and cultured cells of different ploidy fish.

Additional file 6: Table S2. qPCR primers for candidate reference genes.

Additional file 7: Figure S5. Primer melting curves.

\section{Acknowledgements}

The authors would like to express their thanks to the anonymous reviewers for their constructive comments on this manuscript, which have greatly improved its presentation.

\section{Authors' contributions}

YMX, WBL and XDY designed the experiments. WBL, XDY, SLY, LYD, SHD, $J H L, L Y P, M M W$ and $Y T$ carried out the experiments. YMX, WBL, XDY, SLY, JHL and LYP conducted the statistical analysis and discussion. YMX, WBL and XDY organized and wrote the manuscript. All the authors had read the 
paper and agreed to list their names as co-authors. The author(s) read and approved the final manuscript.

\section{Funding}

This work was supported by National Natural Science Foundation of China (31772902, 31802284), National Key Research and Development Program of China (2018YFD0901202), and Key scientific research project of Hunan Provincial Department of Education (19A319).

\section{Availability of data and materials}

The raw data supporting our findings can be found in the NCBI SRA database under the accession number (Accession number: the liver tissue of diploid C. auratus: SRR538839, SRR542431; the liver tissue of triploid hybrid: SRR9185090, SRR9203584; the liver tissue of tetraploid hybrid: SRR1535135, SRR1536195; cultured fin cells of diploid C. auratus: SRR7640868, SRR7640869; cultured fin cells of tetraploid hybrid: SRR7640866, SRR7640867; SP4N cells: SRR9964682, SRR9964683).

\section{Ethics approval and consent to participate}

Not applicable.

\section{Consent for publication}

Not applicable.

\section{Competing interests}

The authors declare that they have no competing interests.

\section{Received: 10 October 2019 Accepted: 31 August 2020} Published online: 17 September 2020

\section{References}

1. Ciesielska A, Stczek P. Selection and validation of reference genes for qRT$P C R$ analysis of gene expression in Microsporum canis growing under different adhesion-inducing conditions. Sci Rep. 2018;8(1):1197.

2. Cui D, Lan QJ, Liu RR. Stability evaluation of reference genes in tissues of Andrias davidianus at different development stages. J Northwest Agric Forestry Univ (Natural Science Edition). 2017;45(10):1-6.

3. Yang LL, Sun Z, Yang LM. Screening of reference genes in Bupleurum scorzonerifolium and tissue expression analysis of key enzyme genes. Chin Herb Med. 2018:49(15):3651-8.

4. McLoughlin KJ, PedriniE MMM, Guduric-Fuchs J, Medina RJ. Selection of a real-time PCR housekeeping gene panel in human endothelial colony forming cells for cellular senescence studies. Front Mede. 2019;6:33.

5. Royer C, Bégin AG, Plawinski L, Lévesque L, Durrieu MC, Laroche G. Validation of reference genes for real-time PCR of cord blood mononuclear cells, differentiating endothelial progenitor cells, and mature endothelial cells. Exp Cell Res. 2018;370(2):389-98.

6. Li B, Matter EK, Hoppert HT, Grayson BE, Seeley RJ, Sandoval DA Identification of optimal reference genes for RT-qPCR in the rat hypothalamus and intestine for the study of obesity. Int J Obes. 2014; 38(2):192

7. Hadadi E, Souza LEB, Bennaceur-Griscelli A, Acloque H. Identification of valid reference genes for circadian gene-expression studies in human mammary epithelial cells. Chronobiol Int. 2018;35(12):1689-701.

8. Jameson PE. Selection of reference genes for flowering pathway analysis in the masting plants, Celmisia lyallii and Chionochloa pallens, under variable environmental conditions. Sci Rep. 2019:9(1):9767.

9. Tang PA, Duan JY, Wu HJ, Ju XR, Yuan ML. Reference gene selection to determine differences in mitochondrial gene expressions in phosphinesusceptible and phosphine-resistant strains of Cryptolestes ferrugineus, using qRT-PCR. Sci Rep. 2017:7(1):7047.

10. Collins C, Patel MV, Colvin J, Bailey D, Seal S. Identification and evaluation of suitable reference genes for gene expression studies in the whitefly Bemisia tabaci (Asia I) by reverse transcription quantitative realtime PCR. J Insect Sci. 2014; 14(1):63.

11. Bin S, Pu X, Shu B, Kang C, Luo S, Tang Y, Wu Z, Lin J. Selection of reference genes for optimal normalization of quantitative real-time polymerase chain reaction results for Diaphorina citri adults. J Econ Entomol. 2018;112(1):355-63.
12. Li MY, Wang F, Jiang Q, Wang GL, Tian C, Xiong AS. Validation and comparison of reference genes for qPCR normalization of celery (Apium graveolens) at different development stages. Fronti Plant Sci. 2016;7:313.

13. Tian C, JiangQ WF, Wang GL, Xu ZS, Xiong AS. Selection of suitable reference genes for $\mathrm{QPCR}$ normalization under abiotic stresses and hormone stimuli in carrot leaves. PLoS One. 2015:10(2):e0117569.

14. ZhangK LM, CaoS SY, Long R, Kang J, Yan L, Cui H. Selection and validation of reference genes for target gene analysis with quantitative real-time PCR in the leaves and roots of Carex rigescens under abiotic stress. Ecotoxicol Environ Saf. 2019;168:127-37.

15. Li D, Wu P, He MF. Screening of reference genes in Siniperca chuatsi for qRT-PCR analysis. Life Sci Res. 2016;20(3):214-7.

16. Zhang $J$, Xue LY, Shi JX. Cloning and expression stability evaluation of reference genes in Spanish mackerel (Scomberomorus niphonius). J Biol. 2016:33(3):20-3.

17. Song C, Liu SJ, Xiao J, He W, Zhou Y, Qin Q, Zhang C, Liu Y. Polyploid organisms. Sci China Life Sci. 2012;55(4):301-11.

18. Liu SY, Zhang WL, Lin SX. Research Progress on polyploidy of Misgurnus anguillicaudatus. Mod Agric Sci Technol. 2018;719(9):245-9.

19. Zhang HY, Zhu XW, Hou PQ. Research Progress on polyploidy of Misgurnus anguillicaudatus. Mol Plant Breed. 2019;17(2):606-11.

20. Forrester NJ, Ashman TL. The direct effects of plant polyploidy on the legume-rhizobia mutualism. Ann Bot. 2017;121(2):209-20.

21. Schoenfelder KP, Fox DT. The expanding implications of polyploidy. J Cell Biol. 2015:209(4):485-91.

22. Linder HP, Lehmann CER, Archibald S, Osbome CP, Richardson DM. Global grass ( $P$ oaceae) success underpinned by traits facilitating colonization, persistence and habitat transformation. Biol Rev. 2018;93(2):1125-44.

23. Guo ZH, Ma PF, Yang GQ, Hu JY, Liu YL, Xia EH, Zhong MC, Zhao L, Sun GL, $X u Y X$, et al. Genome sequences provide insights into the reticulate origin and unique traits of woody bamboos. Mol Plant. 2019;12(10):1353-6.

24. Otto SP. The evolutionary consequences of polyploidy. Cell. 2007;131(3): 452-62.

25. Gregory TR, Mable BK. Polyploidy in Animals. In: Gregory TR, ed. The Evolution of the Genome. San Diego: Elsevier; 2015. p. 427-517.

26. Tihon E, Imamura H, Dujardin JC, Van Den Abbeele J. Evidence for viable and stable triploid Trypanosoma congolense parasites. Parasit Vectors. 2017; 10(1):468.

27. Pelin A, Selman M, Aris-Brosou S, Farinelli L, Corradi N. Genome analyses suggest the presence of polyploidy and recent human-driven expansions in eight global populations of the honeybee pathogen $\mathrm{N}$ osema ceranae. Environ Microbiol. 2015:17(11):4443-58.

28. Zhou L, Gui JF. Natural and artificial polyploids in aquaculture. Aquacult Fish. 2017:2(3):103-11.

29. Silva IS, Ghiraldini FG, Veronezi GMB, Mello MLS. Polyploidy and nuclear phenotype characteristics of cardiomyocytes from diabetic adult and normoglycemic aged mice. Acta Histochem. 2018;120(2):84-94.

30. Tanami S, Ben MS, Elkayam A, Mayo A, Bahar HK, Itzkovitz S. Dynamic zonation of liver polyploidy. Cell Tissue Res. 2017;368(2):405-10.

31. Zhang H, Bian Y, Gou X, Zhu B, Xu C, Qi B, Li N, Rustgi S, Zhou H, Han F, et al. Persistent whole-chromosome aneuploidy is generally associated with nascent allohexaploid wheat. Proc Natl Acad Sci. 2013;110(9):3447-52.

32. Bian Y, Yang C, Ou X, Zhang Z, Wang B, Ma W, Gong L, Zhang H, Liu B. Meiotic chromosome stability of a newly formed allohexaploid wheat is facilitated by selection under abiotic stress as a spandrel. New Phytol. 2018; 220(1):262-77

33. Li LF, Liu B. Recent advances of plant polyploidy and polyploid genome evolution. Scientia Sinica Vitae. 2019;49(4):327-37.

34. Li ZH, Yu X, Gao Y. Species polyploidization and epigenetics. Chin Sci Bull. 2010;55(35):3358-66

35. Liu S, Luo J, Chai J, Ren L, Zhou Y, Huang F, Liu X, Chen Y, Zhang C, Tao M, et al. Genomic incompatibilities in the diploid and tetraploid offspring of the goldfish x common carp cross. Proc Natl Acad Sci. 2016;113(5):1327-32.

36. Liu SJ, Sun YD, Zhang C, Luo KK, Liu Y. Triploid crucain carp-allotetraploid hybrids (male) x goldfish ( hermaphrodite). Acta Genet Sin. 2004;31(1):31-8.

37. Zhang C, Liu SJ, Sun YD, Xiao J, Qin QB, Wang J, He WG, You CP, Liu Y. Chromosomal studies of germ cells in diploid and polyploid fish produced by distant crossing. J Mol Cell Biol. 2008;41(1):53-60.

38. Ren L, Li W, Tao M, Qin Q, Luo J, Chai J, Tang C, Tang C, Xiao J, Tang $X$, et al. Homoeologue expression insights into the basis of growth 
heterosis at the intersection of ploidy and hybridity in Cyprinidae. Sci Rep. 2016;6:27040.

39. Duan W, Xu K, Hu FZ, Zhang Y, Wen M, Wang J, Tao M, Lou KK, Zhao RR, Qin $\mathrm{QB}$, et al. Comparative proteomic, physiological, morphological and biochemical analyses reveal the characteristics of the diploid spermatozoa of allotetraploid hybrids of carassius auratus and common carp (cyprinus Carpio). Biol Reprod. 2015;94(2):35.

40. Zhou Y, Wang M, Jiang M, Peng L, Wan C, Liu W, Zhao R, Zhao X, Hu W, Liu S, et al. Autotetraploid cell line induced by SP600125 from crucian carp and its developmental potentiality. Sci Rep. 2016;6:21814.

41. Mo Y, Fan Y, Fu W, Xu W, Chen S, Wen Y, Liu S, Peng L, Xiao Y. Acute immune stress improves cell resistance to chemical poison damage in SP600125-induced polyploidy of fish cells in vitro. Fish Shellfish Immunol. 2019;84:656-63.

42. Zhang $\mathrm{H}$, Ericsson $\mathrm{M}$, Westrom $\mathrm{S}$, Vahlquist $\mathrm{A}$, Virtanen $\mathrm{M}$, Torma $\mathrm{H}$. Patients with congenital ichthyosis and TGM1 mutations overexpress other ARCI genes in the skin: Part of a barrier repair response? Exp Dermatol. 2019; 28(10):1164-71.

43. Ma X, Wang G, Zhai Z, Zhou P, Hao Y. Global Transcriptomic analysis and function identification of Malolactic enzyme pathway of lactobacillus paracasei L9 in response to bile stress. Front Microbiol. 2018:9:1-11.

44. Galiveti CR, Rozhdestvensky TS, Brosius J, Lehrach H, Konthur Z. Application of housekeeping npcRNAs for quantitative expression analysis of human transcriptome by real-time PCR. Rna. 2010;16(2):450-61.

45. Zhao $Y$, Z Zhang Y, Cao MY. Selection and evaluation of reference genes in quantitative pcr analysis of microrna in. J Nucl Agricult Sci. 2017;31 (7):1299-309.

46. Kaur R, Gupta M, Singh S, Pandher S. Evaluation and validation of experimental condition-specific reference genes for normalization of gene expression in Asia III-I Bemisia tabaci (Gennadius) (Hemiptera: Aleyrodidae). Gene Express Pattern. 2019:34:1-8.

47. Selvarajah GT, Bonestroo FAS, Sprang EPM, Kirpensteijn J, Mol JA. Reference gene validation for gene expression normalization in canine osteosarcoma: a geNorm algorithm approach. BMC Vet Res. 2017;13(1):354-62.

48. Yang WJ, Bing HE, Jie DY. Analysis method of systematically evaluating stability of reference genes using geNorm, NormFinder and BestKeeper. Modern Agricult Sci Technol. 2017;5:278-81.

49. Wu YL, Yang YK, Tan SW. Stability evaluation of reference genes in grass carp (Ctenopharyngodon idellus) liver under acute cadmium exposure. Acta Ecologiate Animals Domastici. 2018;39(194):16-9.

50. Jin Y, Liu F, Huang W, Sun Q, Huang X. Identification of reliable reference genes for qRT-PCR in the ephemeral plant Arabidopsis pumila based on fulllength transcriptome data. Sci Rep. 2019;9(1):8408.

51. Xu X, Liu X, Chen S, Li B, Wang X, Fan C, Wang GQ, Ni HW. Selection of relatively exact reference genes for gene expression studies in flixweed (Descurainia sophia) by quantitative real-time polymerase chain reaction. Pesticide Biochem Physiol. 2016;127:59-66.

52. Moreira VS, Soares VL, Silva RJ, De Sousa AO, Otoni WC, Costa MG. Selection and validation of reference genes for quantitative gene expression analyses in various tissues and seeds at different developmental stages in Bixa orellanaL. Physiol Mol Biol Plants. 2018;24(3):369-78.

53. Huang JF, Liu CQ. Molecular evolution studies: the relationship between fractal and molecular evolution of II.5SrRNA sequences. Acta Zool Sin. 1992; 38(3):334-8.

54. Weigand AM, Dinapoli A, Klussmannkolb A. 18SrRNA variability map for Gastropoda. J Molluscan Stud. 2012;78(1):151-6.

55. Zhang WW, Lu WW, Wang T, Zhao YW, Zhang PF, Wang XY, Chen W, Huang YQ. Effects of different types and levels of oil on the expression of $18 \mathrm{~S}$ rRNA in broilers. Acta Zoonutrimenta Sinica. 2014;26(12):3814-20.

56. Inada T. Quality control systems for aberrant mRNAs induced by aberrant translation elongation and termination. Biochim Biophys Acta. 2013;1829(6): 634-42.

57. Xu R, Zheng X. Selection of reference genes for quantitative real-time PCR in Octopus minor (Cephalopoda: Octopoda) under acute ammonia stress. Environ Toxicol Pharmacol. 2018;60:76-81.

58. Zhao $H$, Zhang $C Y$, Wen $Y$. Screening of reference genes in sesame during Macrophomina phaseolina infection. Chin J Oil Crop Sci. 2017:39(3):393.

59. Svingen $T$, Letting $H$, Hadrup N, Hass U, Vinggaard AM. Selection of reference genes for quantitative RT-PCR (RT-qPCR) analysis of rat tissues under physiological and toxicological conditions. PeerJ. 2015;3:e855.

60. Zhang JH, Cui W. Progress in research on ribosomal protein S5 (RPS5) gene. Livestock Poultry Industry. 2007;1:19-21.
61. Wang J, Ye LH, Liu QZ, Peng LY, Liu W, Yi XG, Wang YD, Xiao J, Xu K, Hu FZ. Rapid genomic DNA changes in allotetraploid fish hybrids. Heredity. 2015;114:601.

62. Xu K, Wen M, Duan W, Ren L, Hu F, Xiao J, Wang J, Tao M, Zhang C, Wang $\mathrm{J}$, et al. Comparative analysis of testis transcriptomes from triploid and fertile diploid cyprinid fish. Biol Reprod. 2015;92(4):1-12.

63. Yan L, Su J, Wang Z, Yan X, Yu R. Selection of reference genes for expression analysis of Kumamoto and Portuguese oysters and their hybrid. J Ocean Univ China. 2017;16(6):1139-47.

64. Sun D, Wan X, Pan BB, Sun Q, Ji XB, Zhang F, Zhang H, Cao CC. Bioinformatics Analysis of Genes and Pathways of CD11b $+/$ Ly6C intermediate Macrophages after Renal Ischemia-Reperfusion Injury. Curr Med Sci. 2018;38(1):70-7.

65. Caracausi M, Piovesan A, Antonaros F, Strippoli P, Vitale L, Pelleri MC. Systematic identification of human housekeeping genes possibly useful as references in gene expression studies. Mol Med Rep. 2017;16(3):2397-410.

66. Hu Y, Lu C, Wei CC, Xiu JF, Wu JW. Cloning and expression pattern of ribosomal protein $\$ 18$ gene in Musca domestica. Biotechnol Bull. 2016;32(6): $152-42$.

67. Moon K, Lee SH, Kim YH. Validation of quantitative real-time PCR reference genes for the determination of seasonal and labor-specific gene expression profiles in the head of Western honey bee, Apis mellifera. PloS one. 2018; 13(7):e0200369.

68. Lü J, Chen S, Guo M, Ye C, Qiu B, Yang C, Pan H. Selection of appropriate reference genes for RT-qPCR analysis in Propylea japonica (Coleoptera: Coccinellidae). PLoS One. 2018:13(11):e0208027.

69. Cao TF, Cong M, Li ZY. Selection of reference genes for toxicological mechanism research on Ruditapes philippinarum exposed to ammonia nitrogen. Asian J Ecotoxicol. 2017;12(2):182-90.

70. Jiang $T$, Gao Y, Tong $Z$. Selection of reference genes for quantitative realtime PCR in Lycoris. Acta Hort Sin. 2015;42:1129-38.

71. Trakunram K, Champoochana N, Chaniad P, Thongsuksai P, Raungrut P. MicroRNA isolation by Trizol-based method and its stability in stored serum and cDNA derivatives. Asian Pac J Cancer Prev. 2019;20(6):1641-7.

72. Trapnell C, Roberts A, Goff L, Pertea G, Kim D, Kelley DR, Pimentel H, Salzberg SL, Rinn JL, Pachter L. Differential gene and transcript expression analysis of RNA-seq experiments with TopHat and cufflinks. Nat Protoc. 2012;7(3):562-78.

73. Mortazavi A, Williams BA, McCue K, Schaeffer L, Wold B. Mapping and quantifying mammalian transcriptomes by RNA-Seq. Nat Methods. 2008; 5(7):621-8

74. Palladino SP, Helton ES, Jain P, Dong C, Crowley MR, Crossman DK, Ubogu EE. The human blood-nerve barrier transcriptome. Sci Rep. 2017;7(1):17477

75. Kayis SA, Atli MO, Kurar E, Bozkaya F, Semcan A, Aslan S, Guzeloglu A. Rating of putative housekeeping genes for quantitative gene expression analysis in cyclic and early pregnant equine endometrium. Anim Reprod Sci. 2011; 125(1-4):124-32.

76. Renard M, Vanhauwaert S, Vanhomwegen M, Rihani A, Vandamme $N$, Goossens S, Berx G, Van VP, Haigh JJ, Decaesteker B, Van LJ, et al. Expressed repetitive elements are broadly applicable reference targets for normalization of reverse transcription-qPCR data in mice. Sci Rep. $2018 ; 8(1): 7642$.

\section{Publisher's Note}

Springer Nature remains neutral with regard to jurisdictional claims in published maps and institutional affiliations.

Ready to submit your research? Choose BMC and benefit from:

- fast, convenient online submission

- thorough peer review by experienced researchers in your field

- rapid publication on acceptance

- support for research data, including large and complex data types

- gold Open Access which fosters wider collaboration and increased citations

- maximum visibility for your research: over $100 \mathrm{M}$ website views per year

At $\mathrm{BMC}$, research is always in progress.

Learn more biomedcentral.com/submission 